\title{
Comparative analysis of movements after experimental spinal cord injury treated with amniotic membrane: Pilot study
}

\author{
Neves $\mathrm{MF}^{*}$, Souza $\mathrm{BS}^{2}$, Souza $\mathrm{CCC}^{2}$, Oliveira E ${ }^{2}$, Chaves $\mathrm{DC}^{2}$, Paula AA ${ }^{3}$, Nicodemo $\mathrm{MC}^{4}$, Sant'Anna ${ }^{4}$, Lima $\mathrm{MO}^{1}$ and Arisawa EALS \\ ${ }^{1}$ Laboratory of Sensorimotor Rehabilitation Engineering, Institute of Research and Development (IP\&D), Universidade do Vale do Paraíba, São José dos Campos, Brazil \\ ${ }^{2}$ Biomedicine, Universidade do Vale do Paraíba, São José dos Campos, Brazil \\ ${ }^{3}$ MS, Physical Therapist, Institute of Physical Medicine and Rehabilitation - Rede Lucy Montoro, São José dos Campos, Brazil \\ ${ }^{4}$ Laboratory of Immunology, Institute of Research and Development (IP\&D), Universidade do Vale do Paraíba, São José dos Campos, Brazil
}

\begin{abstract}
Purpose: This study evaluated the action of human amniotic membrane (HAM) in rats after induced spinal cord injury (SCI).

Methods: twenty-five Wistar rats were divided into five groups ( $\mathrm{n}=5)$ : health (healthy animals underwent to surgical procedure simulation), control (C-injury simulation), injury (I - spinal cord injury) and HAM (SCI + immediate application of HAM). We analyzed the effect of application of HAM fragment on SCI using gait speed analysis (kinematics) and the sciatic functional index (SFI) to the animal gait. Both tests were performed in triplicate at 5 and 12 days after the surgery.
\end{abstract}

Results: Movement analyses demonstrated that the groups which received the HAM application showed an increase in average speed (after 12 days) and in the sciatic functional index (at both 5 and 12 days) when compared to other groups.

Conclusion: The gait speed kinematics and the functional gait (SFI) analyses indicated that the application of HAM in induced SCI in rats led to the recovery of motion and functional gait, which suggests a positive action of this biomaterial in SCI sequels.

\section{Introduction}

Spinal cord injury (SCI) is a reduction or loss of motor function and / or sensory trauma of neuronal elements within the spinal canal where the neurological level of involvement may be complete or incomplete [1]. Complete SC injuries are one of the most common causes of loss of movement and sensitivity at and below the level of the lesion. SCI can lead to spinal shock followed by loss all sensory-motor functions, which includes sagging, bladder paralysis and loss of deep tendon reflexes at and below the level of the lesion $[1,2]$. The incomplete SCI wounds are accompanied by varying degrees of motor and sensory loss below the level of injury and may include rectal and bladder paralysis [2].

The incidence of SCI has increased significantly worldwide in recent years. The SCI occurrence is abrupt, unexpected, and severely impairs the quality of life of these individuals [3-5]. About 2.5 million people live with SCI, and around the world, between 250.000 and 500.000 people suffer new injuries and males are most at risk in young adulthood (2029 years) [6]. According to the National Guidelines of the Ministry of Health [7], in Brazil, the incidence coefficient of traumatic spinal injury is unknown and there is no precise data regarding its incidence and prevalence, however it is estimated to occur around 6.000 to 8.000 new cases per year, being $80 \%$ of the victims are men and $60 \%$ are among the 10 to 30 years of age.

Trauma is the most common cause of SCI [6], which may be caused by traffic accidents (50,4\%), falls (23.8\%), injuries associated with sports activities $(9 \%)$, and violence (11.2\%). Non-traumatic injuries can be caused by tumors, infections, vascular disorders, degenerative, and malformations $[7,8]$. SCI sequels may include expenses with high medical treatment for physical and pathological complications, as urinary tract infection, spasticity, chills and fever, decubitus ulcers and autonomic dysreflexia, as well as social complications as job loss and the permanent need for emotional support systems and medical assistance [6,9].

This scenario may lead to the research of new therapeutic approaches to repair SCI using stem cell-based therapies, such as transplantation of stem cells / neural progenitor. Previous studies have reported functional recovery after stem cell transplantation for spinal cord injury in rodents and nonhuman primates [10]. In this context, application of cells or fragments obtained from human Amniotic Membrane (HAM) has gained importance due to their ability to reduce inflammation and scarring and to serve as a substrate for cell proliferation and differentiation [11-14].

Therefore, considering HAM properties could promote tissue repair as a source of stem cell, we have hypothesized that their use after

Correspondence to: Neves MF, Laboratory of Sensorimotor Rehabilitation Engineering, Institute of Research and Development (IP\&D), Universidade do Vale do Paraíba, São José dos Campos, Brazil, E-mail: mneves@univap.br

Key words: spinal cord injury; human amniotic membrane; kinematics analysis; functional gait

Received: March 13, 2018; Accepted: March 27, 2018; Published: March 29, 2018 
SCI could represent a potential new treatment for SCI sequel's in motor function. This study aimed to analyze the functional gait of rats with induced SCI comparing the action of HAM applied immediately after the injury.

\section{Methods}

After approval by the Research Ethics Committee of University of Vale of Paraíba (CAAE: 16381213.2.0000.5503; CEAU n ${ }^{\circ}$ A15), 20 adult male rats (Rattus norvegicus, Albinus, Wistar, 60 days, $230 \pm 20 \mathrm{~g}$ ) were divided into four groups:

1. $\mathrm{H}$ (health - healthy animals who suffered no surgical nor injury procedures, $n=5$ );

2. C (control-simulation procedures surgical, $n=5$ );

3. I (Injury - spinal cord injured animals, $n=5$ );

4. HAM (SCI + immediate application of HAM, $n=5)$ and

The animals stayed in individual cages with a 12:12 light-dark cycle, at controlled temperature $\left(20 \pm 2{ }^{\circ} \mathrm{C}\right)$, feed with diet and water ad libitum. The HAM was obtained from human placentas collected at the Hospital and Maternity of Santa Casa in São José dos Campos, São Paulo, Brazil. All donors signed a Free, Prior, and Informed Consent, as well as met the inclusion criteria and all laboratory procedures for processing HAM occurred in sterile conditions inside a laminar flow cabinet in accordance with the processing protocol described by Sant'Anna, et al. [13]. First, we manually peeled the HAM from the chorion and extensively washed it with saline solution containing $100 \mathrm{U} / \mathrm{ml}$ penicillin, $100 \mathrm{mg} / \mathrm{ml}$ streptomycin, and $2.5 \mathrm{ug} / \mathrm{ml}$ of amphotericin B. Then, we cut the HAM into pieces of $2 \mathrm{~cm} \times 2 \mathrm{~cm}$ and we stored them separately at room temperature in $50 \mathrm{ml}$ tubes containing DMEM (Dulbecco's Modified Eagle's medium) without addition of serum and red phenol, in a sterile condition until the application into the animal $[13,15]$.

\section{Surgical procedures}

Spinal cord injury was induced by direct trauma with a mini guillotine in groups I and HAM following the protocol described by Paula, et al. [16]. We submitted Group $C$ rats only to surgical procedures and simulation of HAM application, without any kind of injury. For the surgical procedures, the animals received intramuscularly $10 \%$ ketamine (anesthetic) associated with xylazine (muscle relaxant) at doses $0.01 \mathrm{ml} / \mathrm{kg}$ and $0.005 \mathrm{ml} / \mathrm{kg}$, respectively. We performed a longitudinal incision $(2.5 \mathrm{~cm})$ in the dorsal region, between $\mathrm{T} 9$ and $\mathrm{T} 10$, to expose and visualize the spinal cord. Hereafter, an impactor system (Figure 1) was used to induce a SCI by dropping the guillotine weight from $25 \mathrm{~mm}$ free fall, causing a trauma injury by direct contusion. Fifteen seconds were waited and then it was removed [16].

After removal the guillotine weight, we applied a $2.5 \mathrm{~cm}$ fragment of HAM in the group of HAM animals. It is emphasized that the MAH fragment was applied with the mesenchymal side in contact with the SCI area, completely covering this region. The edges of HAM fragment were adhered to the surrounding bone tissue with one drop of methacrylate. Tissues are repositioned and sutured with 3-0 polyamide monofilament thread (nylon) suture (Figure 2).

All animals received antibiotic (enrofloxacin, $5 \mathrm{mg} / \mathrm{kg}$ subcutaneously once per day for 4 days) and analgesic therapy (tramadol hydrochloride, $10 \mathrm{mg} / \mathrm{kg}$, intraperitoneally, every 12 hours for 5 days) and housed at heated cage $\left(25^{\circ} \mathrm{C}\right)$ for $45 \mathrm{~min}$ to control the postoperative hypothermia.

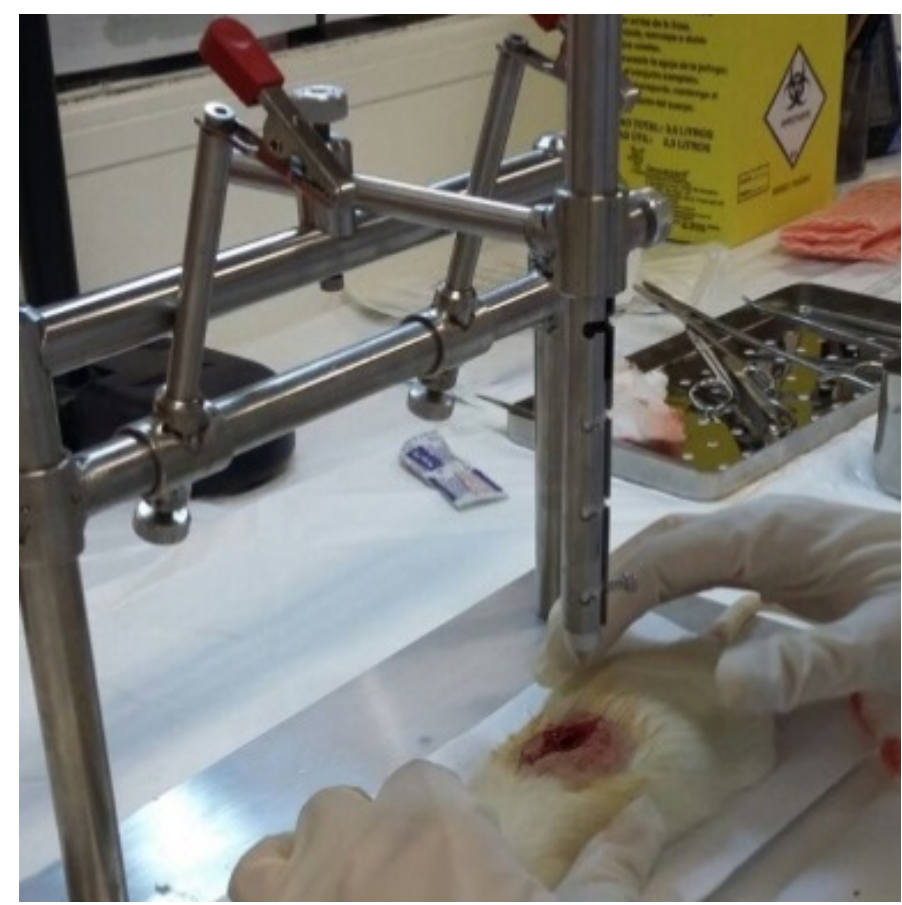

Figure 1. Induction of SCI between T9-T10, by direct trauma, with the use of the mini guillotine.

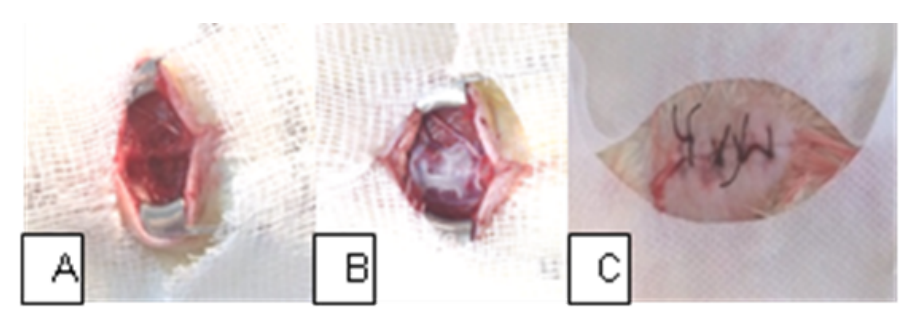

Figure 2. Surgical procedure. (A) T9-T10 area with spinal cord injury; (B) HAM edges attached to the bone tissue around the region of interest; (C) suturing the tissues.

\section{Evaluation of motor function}

Two analyses of movements were performed in triplicate on groups $\mathrm{H}, \mathrm{C}, \mathrm{I}$ and HAM at 5 and 12 days after the surgery. For gait speed analysis (kinematics), we used a box made of acrylic (46 $\mathrm{cm}$ longX 8 $\mathrm{cm}$ wideX30 $\mathrm{cm}$ high) open at the surface. The box was placed in the angle with two cinematic cameras (Optitrack, Flex model: V100 R2) supported on tripods, and positioned laterally to the collection area. For three-dimensional image reconstruction, a reflective marker, adhered to the femur of the mouse's left hind leg, remained visible simultaneously for both cameras. The positioning of the box and the camera was marked on the floor to standardize data collection in relation to cameras and their calibration.

The software Motive (OptiTrack ${ }^{\circledast}$ ) captured the movement of each animal and exported the data in CVS model for analysis in Origin Pro $8.5^{\circ}$ software. Each animal performed the test three times (triplicate) and the average gait speed $(\mathrm{cm} / \mathrm{s})$ was obtained by calculating the linear coefficient held in the analysis software and expressed by mean and standard deviation.

Also, for the sciatic functional index (SFI) run (collected in triplicate), we used the same box (Figure 3). We coupled a dark box at the end of the trial box where the animals headed for refuge. The trial box was suspended, resting on two aluminum stands. A mobile device 


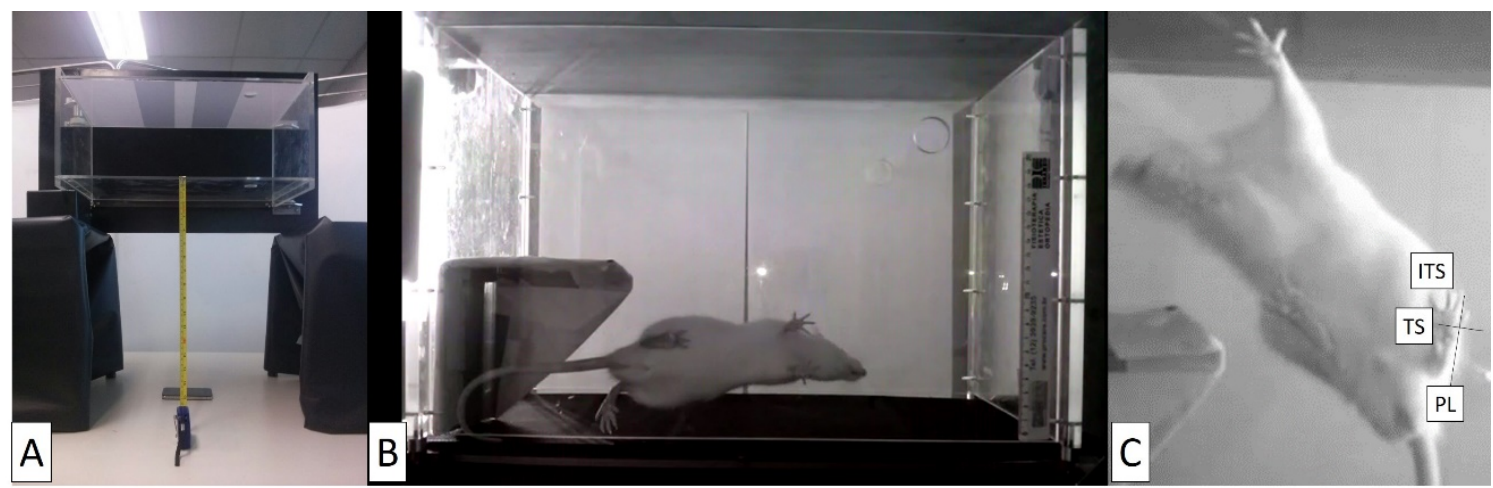

Figure 3. Sciatic functional index (SFI): (A) acrylic box for walk test; (B) Capture motion made by mobile phone using Image J Software; (C) rat print showing the measurements taken: ITS (intermediary toe spreading), TS (toe spreading), PL (print length).

was positioned below, with the camera directed to the center of the acrylic box, enabling the capture of images from the lower plane.

The video images were exported to the computer to capture the "Frame Grabs" (frames) of the phases of the gait and subsequent measurement [17] using Microsoft ${ }^{\circ}$ Windows Movie Maker ${ }^{\oplus}$, Version 5.1 to capture three frames of each animal (triplicate). The frames were stored and exported to the program Image J (Version 1.48, National Institute of Health) to calculate the parameters length of the footprint of the experimental paw (PL), distance between the first and fifth toes of the experimental paw (TS), and distance between the second and the fourth toe of the experimental paw (IT). The SFI values below zero show functional impairment and near -100 configured losses of total function [18].

One-way ANOVA statistical test could be applied after all tests were run in triplicate generating mean and standard deviation values (T-test; $\mathrm{p} \leq 0.05$ ).

\section{Results}

Table 1 and Figure 4 show the motor assessments of the H, C, I and HAM groups, at 5 and 12 days after surgeries represented as mean \pm standard deviation, at significance level $\mathrm{p} \leq 0.05$.

Table 1 shows that 5 days after induced SCI, the injured group (I) had a significant reduced mean velocity when compared to health ( $\mathrm{p}$ $=0.0349)$, to control (0.0480) group. HAM group presented slower movement when compared to health $(\mathrm{p}=0.0449)$ and control $(\mathrm{p}=$ $0.0094)$ at the same experimental time. In the intragroup analyses, both injury group ( $<0.001)$ and HAM group $(\mathrm{p}=0.386)$ had mean gait speed increased, while Control group showed no significant change of mean gait speed. It is important to observe that regarding $12^{\text {th }}$ postoperatory day, there was no significant difference in the intergroup.

Figure 4 presents the data relating Sciatic Functional Index (SFI) to functional gait. The experimental groups I $(n=5)$ and HAM-0 $(n=5)$ showed significant motor impairment of the hind paw when compared to $\mathrm{H}(\mathrm{n}=5)$ and $\mathrm{C}(\mathrm{n}=5)$ groups both 5 and 12 days after surgery $(\mathrm{p}<$ 0.05). Post-operative groups did not differ among themselves at 5 days. However, the movement impairment of HAM group was significantly lower when compared to groups I $(\mathrm{p}=0.0093)$ and at the twelfth postoperatory day. In the intragroup analysis at the same experimental times, only the HAM-0 group showed significant recovery of motor function at the twelfth post-operatory day $(\mathrm{p}=0.0335)$.

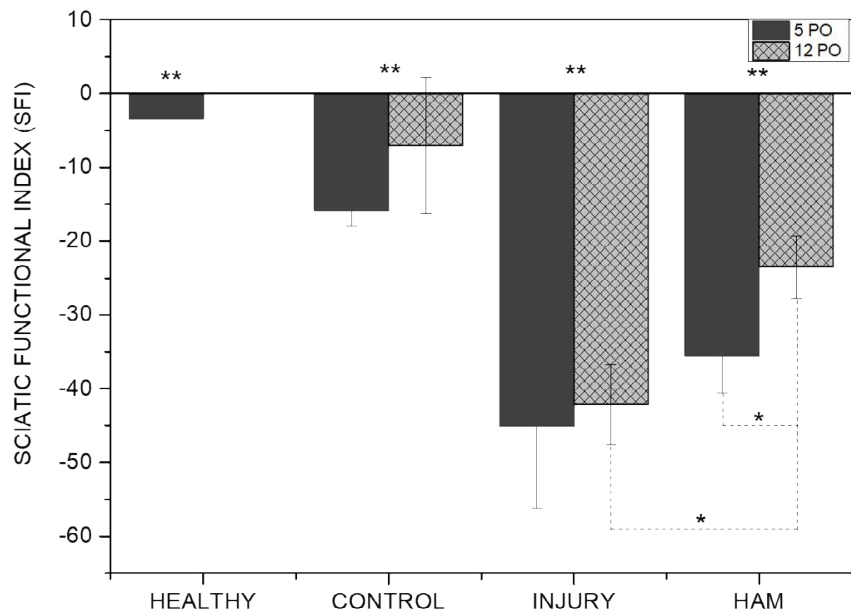

Figure 4. Sciatic Functional Index (SFI) columns for health, control, injury, HAM-0, and HAM- 8 groups 5 and 12 days after SCI surgery. ${ }^{*} \mathrm{p}<0.05, * * \mathrm{p}<0.001$. HAM (Human amniotic membrane), PO (Post-operatory).

Table 1. Average gait speed by motion analysis (kinematics) of speed $(\mathrm{cm} / \mathrm{s})$ expressed by mean and standard deviation for the control, injury and HAM groups, at 5 and 12 days after surgery. $(* \mathrm{p}<0.05),(* * \mathrm{p}<0.001)$.

\begin{tabular}{|c|c|c|c|c|}
\hline & Health $(\mathbf{n = 5})$ & $\begin{array}{c}\text { CONTROL } \\
(\mathbf{n = 5})\end{array}$ & INJURY (n=5) & $\begin{array}{c}\text { HAM } \\
(\mathbf{n}=\mathbf{5})\end{array}$ \\
\hline $\mathbf{5}^{\text {th }}$ post-operatory & $6.9 \pm 0.4$ & $6.8 \pm 2.3$ & $4.1 \pm 0.9^{*}$ & $4.2 \pm 1.8^{*}$ \\
\hline $\mathbf{1 2}^{\text {th }}$ post-operatory & Not applied. & $5.1 \pm 0.8$ & $7.3 \pm 4.1^{* *}$ & $8.6 \pm 2.8^{* *}$ \\
\hline
\end{tabular}

\section{Discussion}

This is an innovative study evaluating the effect of human amniotic membrane (HAM) fragments applied immediately (HAM group) after the induction of spinal cord injuries in rats. The application of a HAM fragment aimed to preserve the tissue microenvironment of this biomaterial, since it contains several growth factors and undifferentiated mesenchymal cells, on the assumption that this would facilitate the repair of nervous tissue lesion [11-14]. Further, the application of HAM in fragments requires less manipulation than the application of stem cells, keeping the growth factors present in it microenvironment could stimulate the differentiation of mesenchymal cells as response to stimuli received from the injured tissue [13]. The number and viability of cells in the human amniotic membrane fragments, when stored for $24 \mathrm{~h}$, suffer no significant change when compared to the fresh membrane [12]. 
The application of HAM immediately after the induction of SCI aimed to evaluate possible differences in the action of the biomaterial applied immediately after the injury. From our results, we verified that the application of HAM was effective to improve gait speed and functional gait after induced SCI in rats.

SCI can cause loss of neurological functions that affect all levels at and below the injury site, which means that the movements and sensations can be totally or partially reduced below the lesion area [19]. The inflammatory process following trauma can start a secondary lesion characterized by edema, hemorrhage, progressive tissue loss, neuronal loss, and glial cell dysfunctions [16]. The recovery process in humans is limited and not very functional, because the tissue environment that hinders the regenerative process of the axon $[19,20]$.

SCI is also associated with motor and sensory symptoms that lead to changes in posture and gait. The recovery of the gait is one of the main goals of rehabilitation treatment from the point of view of patients and therapists [21].

Researchers have proposed several therapeutic strategies to repair secondary injury via spinal cord regeneration and neuronal growth [22]. In this context, SCI treatment protocols have evolved a plurality of options, such as anti-inflammatory non-steroidal drugs; physiotherapy; Low-Level Laser Therapy (LLLT); ultrasound; corticosteroid injections; shock wave therapy; surgery; biomaterials, growth factor and stem cell application [14,16,20,23].

Up to this moment the reports in the literature pertaining to neurological tissue repair involving the amniotic membrane are still scarce. Although, there are consistent reports of its effectiveness when applied, in the clinical ophthalmology field [24]; as a fragment, about ischemic heart of rats [12]; on the experimental biliary fibrosis of rats, reducing the degeneration fibrotic [13]; about inducted lesion in mouse Achilles tendon [14], among others.

A pilot study from Oliveira, et al. which investigated by histopathological qualitative analysis the application of the HAM fragment in rats SCI, could observe that the HAM visibly reduced the formation of cavitation with cystic aspect, determining less destruction of the spinal cord tissue, with consequent preservation of healthy tissue, when compared to the animal who did not receive HAM after SCI. They also observed the reduced presence of chronic inflammatory infiltrate in the animals of the HAM group, which was a positive response factor, considering that the presence of these cells after the 28-day period would be classified as a chronic response, and could lead to tissue degeneration and necrosis, as well as the formation of large cavities in the nerve tissue, with consequent loss of coordinated functions.

The kinematic analysis demonstrated that the HAM did not differ from health and control groups. However, the HAM group showed a significant increase in average speed on the 12th day after the induced SCI, which was confirmed by improved function observed by the SFI (Table 1). The gait evolution of groups with the HAM suggests a promising positive action of this biomaterial in the repair of nervous tissue.

Other studies showed that HAM has other properties that can aid in tissue repairs, such as anti-adhesive effect, wound protection, adhesion and migration of basal epithelial cells, reduction of fibrosis, prevention of apoptosis, and restoration of the epithelial phenotype. HAM also contains various growth factors, which stimulate re-epithelialization $[24,25]$.
According to Nicodemo, et al. [14] the use of HAM in wound healing in Achilles tendon of rats proved to be very efficient, because there was no increased induction in the inflammatory response, and HAM presented excellent biocompatibility with the injured tendon tissue. Histological analysis of histological sections showed that HAM fragment was incorporated into the area of tendon injury after 7 days, and the number of mature fibroblasts and collagen fibers significantly increased compared to the injured group at $14^{\text {th }}$ day.

Bottai, et al. [26] analyzed the effects of amniotic fluid cells in the third trimester of pregnancy applied in rats with spinal cord injury. These cells grew in different culture media and when transplanted to animals, some of the tested samples were able to induce significant improvement in motor recovery Basso Mouse Scale (BMS). The improved motor functional recovery shows a correlation to the greater preservation of myelin in the ventral horn of white matter and increased vascularization in the peri-wound area.

According to Brown, et al. [27] HAM is a biologically active tissue and has been used to repair myelomeningocele (MMC) in human fetuses. In their study, sheep fetuses underwent surgical creation of MMC at the gestational age of 75 days followed by intrauterine repair at the gestational age of 100 days. The lambs recovered after applying a fragment of autologous HAM, followed by skin closure. The autopsy and histopathology of the spinal cords showed an increase in motor neurons and decreased scarring of wounds in the skin.

Our results are consistent with the properties described for HAM in several studies. HAM acts in the tissue repair process probably as a "basement membrane transplant", as a substrate for cell proliferation that occurs after spinal cord injury. Articles previously mentioned showed the action antibacterial, anti-inflammatory and inhibitory of proteinase of HAM, as well as the presence of various growth factors such as EGF, TGF-, HGF, which stimulate and promote the functional recovery $[13,14,24,25,28]$.

The high availability and ease of obtaining HAM makes this biomaterial an excellent option for the treatment of SCI. However, clinical application depends on the validation of new controlled experimental studies.

\section{Conclusion}

The results of this study suggested that HAM could repair surgically induced spinal cord injuries in rats, and lead to better performance in the recovery of average speed gait and sciatic functional index.

\section{References}

1. American Spinal Injury Association (ASIA) (1999) Standards for neurological and functional classification of spinal cord injury. Medical Society of Paraplegia.

2. Fujimoto Y, Abematsu M, Falk A, Tsujimura K, Sanosaka T, et al. (2012) Treatment of a Mouse Model of Spinal Cord Injury by Transplantation of Human Induced Pluripotent Stem Cell-Derived Long-Term Self-Renewing Neuroepithelial-Like Stem Cell. Regenerative Medicine. Stem Cells 30: 1163-1173. [Crossref]

3. Leucht P, Fischer K, Muhr G, Mueller EJ (2009) Epidemiology of traumatic spine fractures. Injury 40: 166-172. [Crossref]

4. Bampi LN, Guilhem D, Alves ED (2010) Social model: a new approach of the disability theme. Rev Lat Am Enfermagem 18: 816-823. [Crossref]

5. Thuret S, Moon LDF, Gage FH (2006) Therapeutic interventions after spinal cord injury. Nat Rev Neurosci 7: 628-643. [Crossref]

6. WHO (2017), world health day, World Health Organization.

7. Guidelines for attention to person with spinal cord injury (2015) Ministry of Health Secretariat for Health Care/ Department of Strategic programmatic actions, Brazilia. 
8. van den Berg ME, Castellote JM, de Pedro-Cuesta J, Mahillo-Fernandez I (2010) Survival after Spinal Cord Injury: A Systematic Review. J Neurotrauma 27: 15171528. [Crossref]

9. Adams M, Cavanagh JF (2013) International Campaign for Cures of Spinal Cord Injury Paralysis (ICCP): another step forward for spinal cord injury research. Spinal Cord 5: 273-280.

10. Nori S, Okada Y, Yasuda A, Tsuji O, Takahashi Y, et al. (2011) Grafted human-induced pluripotent stem-cell-derived neurospheres promote motor functional recovery after spinal cord injury in mice. Proc Natl Acad Sci U S A 108: 16825-16830. [Crossref]

11. Niknejad H, Peirovi H, Jorjani M, Ahmadiani A, Ghanavi J, et al. (2008) Properties of the amniotic membrane for potential use in tissue engineering. Eur Cell Mater 15: 88-99. [Crossref]

12. Cargnoni A, Di Marcello M, Campagnol M, Nassuato C, Albertini A, et al. (2009) Amniotic Membrane Patching Promotes Ischemic Rat Heart Repair. Cell Transplant 18: 1147-1159. [Crossref]

13. Sant'Anna LB, Cargnoni A, Ressel L, Vanosi G, Parolini O (2011) Amniotic Membrane Application Reduces Liver Fibrosis in a Bile Duct Ligation Rat Model. Cell Transplant 20: 441-453. [Crossref]

14. Nicodemo MC, Neves LR, Aguiar JC, Brito FS, Ferreira I, et al. (2016) Amniotic membrane: An option for treatment of acute Achilles tendon injury in rats. Connective Tissue Research.

15. Hennerbichler S, Reichl B, Pleiner D, Gabriel C, Eibl J, et al. (2007) The influence of various storage conditions on cell viability in amniotic membrane. Cell Tissue Bank 8: 1-8. [Crossref]

16. Paula AA, Nicolau RA, Lima Mde O, Salgado MA, Cogo JC (2014) Low-intensity laser therapy effect on the recovery of traumatic spinal cord injury. Lasers Med Sci 29: 1849-1859. [Crossref]

17. Franco R, Raimundo SS, Belo MAA, de Moraes FR, Mota FCD, et al. (2011) Avaliação de método digital para análise do índice funcional do ciático em ratos. Biosci J 27: 305-331.
18. Medinaceli L, Freed WJ, Wyatt RJ (1982) An index of the functional condition of rat sciatic nerve based on measurements made from walking tracks. Exp Neurol 77: 634643. [Crossref]

19. Andrade MSR, Hanania FR, Daci K, Leme RJA, Chadi G (2008) Contuse lesion of the rat spinal cord of moderate intensity leads to a higher time-dependent secondary neurodegeneration than severe one an open-window for experimental neuroprotective intervention. Tissue Cell 40: 143-156. [Crossref]

20. Wang M, Zhai P, Chen X, Schreyer DJ, Sun X, et al. (2011) Bioengineered scaffolds for spinal cord repair. Tissue Eng Part B Rev 17: 177-194. [Crossref]

21. Fonseca NM, Mandim BL, Ruzi RA, Tavares FR (2006) Bloqueio do nervo isquiático por abordagem posterior simplificada no ponto médio do sulco glúteo-femora: estudo com diferentes volumes de lidocaína a 1\%. Rev Bras Anestesiol 56: 230-238.

22. Rodrigues NR, Letaif OB, Cristante AF, Marcon RM, Oliveira RP, et al. (2010) Padronização da lesão de medula spinal em ratos wistar. ActaOrtop Bras 18: 182-186.

23. Zeman RJ, Wen X, Ouyang N, Rocchio R, Shih L, et al. (2008) Stereotactic radiosurgery improves locomotor recovery after spinal cord injury in rats. Neurosurgery 63: 981987. [Crossref]

24. Tseng, SCG (2001) Amniotic Membrane Transplantation for Ocular Surface Reconstruction. Biosci Rep 21: 481-489. [Crossref]

25. Manuelpillai U, Moodley Y, Borlongan CV, Parolini O (2011) Amniotic membrane and amniotic cells: Potential therapeutic tools to combat tissue inflammation and fibrosis? Placenta 4: S320-S325. [Crossref]

26. Bottai D, Scesa G, Cigognini D, Adami R, Nicora E, et al. (2014) Third trimester NG2 positive amniotic fluid cells are effective in improving repair in spinal cord injury. Exp Neurol 254: 121-133. [Crossref]

27. Brown EG, Saadai P, Pivetti CD, Beattie MS, Bresnahan JC, et al. (2014) In utero repair of myelomeningocele with autologous amniotic membrane in the fetal lamb model. J Pediatr Surg 49: 133-137. [Crossref]

28. Cremonini DN, Ranzani JJT, Marques MEA, Rodrigues GN, Brandão CVS (2007) Transplantation of cryopreserved canine amniotic membrane for cicatrisation in cornea with limbal stem cells deficiency in rabbits. Arq Bras Med Vet Zootec 59: 1462-1467.

Copyright: $(2018$ Neves MF. This is an open-access article distributed under the terms of the Creative Commons Attribution License, which permits unrestricted use, distribution, and reproduction in any medium, provided the original author and source are credited. 